\title{
Incidente de negocios DISTRIBUIDOR CONQUISTADO, VENTA REALIZADA
}

\author{
David Solano, M.A. ESAN
}

M aicito Perú S.A. es una empresa del rubro de alimentos. Produce y comercializa todo tipo de derivados de maíz, además de importar otros productos.

En el mes de noviembre de un año determinado, durante una reunión de gerencia donde participan el gerente general, el gerente de producción, el gerente de marketing y el jefe de planta, se produce el siguiente diálogo:

Gerente de producción: Señores, todos sabemos que la avena demora mucho en cocinarse y que las amas de casa invierten mucho tiempo en preparar el desayuno, $i$ no es así?

Gerente general: Lo cual es un problema para las que tienen que salir a trabajar.

Gerente de producción: Exacto. Pero nosotros hemos encontrado cómo facilitarles el trabajo. Tenemos en mente un nuevo producto. Agregaremos "Fe- culina"t/a la avena y la convertiremos en avena instantánea. Bastará sólo agua, un hervor y listo. Sera una crema muy nutritiva y, sobre todo, habremos lanzado un producto novedoso. La ventaja para nosotros es que el proceso de producción es muy sencillo y barato y nos reportará utilidades respetables.

Gerente de marketing: ¿Perotendráaceptación el producto?

Gerente gencral: Claro que sí. Toda ama de casa estaráagradecida de que le ahorremos tiempo por las mañanas. Además. ya hemos registrado la patente del producto. Mi pregunta es qué estrategia usaremos para su venta.

Gerente de marketing: $\iota$ El producto ya tiene nombre?

I/ Alimento de consumo final elaborudo a base de fécula de maíz. Es el producto más importante de Maicito Perú S.A. y uno de los líderes del mercado en su segmento. 
Gerente general: Sí, se llama "Pastita".

Gerente de marketing: Yo creo que debemos usar a una empresa comercializadora; nuestra fuerza de ventas está ocupada con nuestros otros productos.

Gerente general: Cierto. ¿Cuál crees que podría ser?

Gerente de marketing: ¿Por qué no RISA? Es una de las más grandes de Lima y maneja muchos productos, entre ellos algunos líderes del mercado. Ya hemos urabajado con ella anteriormente; su equipo de ventas es muy bueno y mantiene una excelente relación con sus clientes.

Gerente general: Creo que este producto tendriamos que lanzarloen grande. Ganaríamos prestigio a los ojos de Maicito Corporation ${ }^{2} \cdot{ }_{2}$ Recuerdan que les conté cómo una vez en Brasil organizaron una gran fiesta para presentar un nuevo producto, $\mathrm{e}$ inclusive daban premios a aquel los que compraban grandes cantidades?

Gerente de marketing: Listo. Será todo un acontecimiento. Invitaremos al distribuidor y a los principales clientes. Dará mucho que hablar.

Gerente general: Pues bien, manos a la obra, pero que sea en febrero. Como ustedes saben, dentro de algunos días iniciaré mi visita a las diferentes plantas de la corporación y estaré fuera del país unos tres meses.

2/ Transnacional a la que pertenece Maicito.

\section{Al año siguiente...}

\section{Primera semana de febrero}

Maicito Perú S.A. presenta su nuevo producto, "Pastita", en una gran fiesta en la cual invierte poco más de cien mil dólares. Entre los asistentes se encuentran representantes de las tiendas, bodegas y supermercados más conocidos. Esa noche se venden aproximadamente cien toneladas de "Pastita" y se presentan los comerciales que se difundirán a través de la radio y la televisión a partir del día siguiente. los que destacan principalmente la rapidez de preparación del producto. Se sortean premios millonarios: refrigeradoras, autos, viajes al interior del pais.

El producto se distribuye en bolsas de 0,45 y de 10 kilogramos. Su precio es 25 por ciento más alto que el de la avena tradicional y se vende en todos los distritos de Lima. En autoservicios la venta se apoya con degustación de cortesía. Además, a manera de promoción se adjunta bolsitas de 0,55 kilogramos al producto más exitoso de la fábrica: "Feculina", que se vende directamente a los mayoristas a nivel nacional.

\section{Cuarta semana de febrero}

Reina gran alegría en la fábrica. En las dos últimas semanas se han colocado 55 toneladas más del producto, superando todas las expectativas. $\mathrm{El}$ hecho es comunicado vía facsímile al gerente general, a la sazón de visita en la sede de Maicito Corporation.

Elgerente de producción no puedecontener su entusiasmo $\mathrm{e}$ inmediatamente se pone en contactocon la empresa encargada 
del embolsado de "Pastita". "En caso de seguir las cosas así, tenemos chamba para rato", le dice al gerente de esa empresa. También le comenta que recién cuando regrese el gerente general nombrarán una persona que se encargue de supervisar $\mathrm{el}$ embolsado, ya que actualmente no disponen del personal necesario.

Por esos días, en conversaciones informales durante los momentos de descanso, el jefe de planta repara en que los trabajadores de Maicito no consumen "Pastita", que siguen comprando avena. Aducen que es demasiado cara y muy dificil de preparar, que se les quema. "Qué quiere, ingeniero. $\mathrm{Ni}$ aquí ni en las tiendas se explica cómo se cocina". El hecho le sorprende, pero se abstiene de comentarlo.

\section{Primera semana de abril}

Ya que el acuerdo con el distribuidor incluye una cláusula que especifica que el cliente puede devolver el producto por expiración o deterioro, en las últimas dos semanas han llegado a la fábrica cerca de 90 toneladas en devolución. Las causas principales son el deterioro de las bolsas (roturas). Algunas tienen visos de haber sido abiertas intencionalmente y otras muestran huellas o indicios de haberse reventado. Este producto vuelve a entrar en línea para ser reembolsado.

El gerente de producción se muestra extrañado por el hecho que el distribuidor no haya informado de problemas con el envase ni haya transmitido las quejas de las . tiendas. Consulta con el gerente de marketing y éste le recomienda hablar con la encargadade la coordinación entre Maicito y RISA. Esta señorita le manifiesta no estar enterada del asunto, a pesar de estar casi todo el día en las oficinas de RISA y de haber hecho muy buenos amigos ahí.

Por otro lado, las devoluciones de "Feculina" se han elevado en cerca de 50 por ciento, sobre todo de lotes producidos antes de febrero de 1995. El jefe de planta ha escuchado rumores en el sentido de que algunos minoristas deterioran a propósito el producto para poder devolverlo y luego beneficiarse con el envase de 0,55 kilogramos de "Pastita" que viene adherido a "Feculina".

Debe señalarse que "Pastita" expira seis meses después de ser producido.

\section{Segunda semana de abril}

De regreso de Chile y puesto al tanto de lo que sucede, el gerente general convoca de inmediato al gerente de producción, al gerente de marketing y al jefe de planta a una reunión de urgencia donde plantea las siguientes preguntas:

- ¿Qué sucede? ¿Por qué tanta devolución? $-i$ El producto responde a las necesidades del público? ¿Por qué?

- ¿En qué está fallando la fábrica respecto a comunicación y al distribuidor?

- ¿Debía el distribuidor comunicar las quejas de los clientes? Y si es así, ¿por qué no lo hace? 


\section{NOTA PEDAGÓGICA}

El incidente se presta para un análisis eminentemente cualitativo. Ha sido desarrollado para ilustrar la forma como debe estructurarse el marketing mix de una empre$\mathrm{sa}$, tomando en cuenta no sólo el producto que se piensa lanzar al mercado, sino también la cartera de clientes con que cuenta la empresa. El incidente debe resolverse desde el punto de vista del gerente de marketing, partiendo de la situación final.

Otro aspecto interesante por analizar es el estilo de toma de decisiones -que se refleja claramente en el diálogo inicial-y su influencia en las decisiones de marketing.

Además de las preguntas de discusión planteadas en el incidente, es importante también responder las siguientes:

- ¿Es el producto adecuado para las necesidades que pretende cubrir?

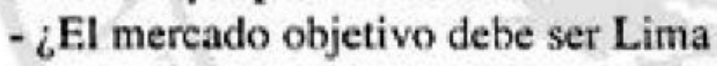
Metropolitanaosóloalgunos distritos? ${ }_{i}$ Por qué? $-\succsim$ Cuáles son los inconvenientes de trabajar un producto nuevo con fuerza de distribución externa a la empresa? ¿Cómo se pueden solucionar los problemas que surjan?

- ¿Cómo debe ser la comunicación de un producto nuevo? ${ }_{i}$ Cuál debe ser el público objetivo?

-¿Quién es el cliente?, ¿el distribuidor, el minorista o el consumidor final?

- ¿Cómo se debe usar los trabajadores como canales de comunicación?

La solución del incidente debe culminar con la propuesta del marketing mix que se debe implementar para "Pastita" y el planteamiento de las acciones que deben llevarse a cabo para ello, tanto al interior como al exterior de la empresa. Como toda discusión cualitativa, existirán muchas respuestas válidas, siendo mucho más importante el análisis de la situación. 